\title{
Additional cleft mitral valve diagnosed by a combination of 2-D and 3-D echocardiography using transesophageal echocardiography during mitral valve prolapse: a case report
}

Kazuto Miyata* and Sayaka Shigematsu

\begin{abstract}
Background: A mitral cleft may be an important etiological factor for significant mitral regurgitation. We diagnose an additional cleft mitral valve by a combination of 2-dimensional (2-D) and 3-dimensional (3-D) echocardiography.

Case presentation: We describe the case of a severe mitral regurgitation due to posterior leaflet prolapse (P2). In the 2-D view, which is obtained after turning the probe clockwise from the mid-esophageal long-axis view, TEE showed a moderate central regurgitation jet. In the 3-D en face view, a cleft between P2 and P3 was identified, and we found that the cause of mitral regurgitation was not only P2 prolapse but also a cleft between P2 and P3.

Conclusion: A complex mitral valve lesion was detected by a combination of 2-D and 3-D TEE. The presence of a cleft could affect the surgical procedure because of the possibility that an enlarged cleft would increase with leaflet resection.
\end{abstract}

Keywords: Mitral valve prolapse, Cleft mitral valve, Mitral valve repair

\section{Background}

Cleft mitral valve is a rare finding in adult cardiovascular medicine. The accurate diagnosis of complex mitral valve lesions is important for mitral valve repair [1]. However, no standard method has been proposed for diagnosing the etiology of mitral regurgitation, especially a cleft, by transesophageal echocardiography (TEE).

\section{Case presentation}

A 51-year-old man (height $168 \mathrm{~cm}$; weight $57 \mathrm{~kg}$ ) had severe mitral regurgitation due to posterior leaflet prolapse (P2) with exertional dyspnea. He had normal systolic function (ejection fraction 75\%) with no past history. He was scheduled to undergo robot-assisted mitral valve repair.

\footnotetext{
* Correspondence: kmiyata0410@gmail.com

Department of Anesthesia, New Heart Watanabe Institute, Hamadayama 3-19-11, Suginami-ku, Tokyo 168-0065, Japan
}

General anesthesia was induced with $5 \mathrm{mg}$ of midazolam, $50 \mathrm{mg}$ of rocuronium, and $0.5 \mu \mathrm{g} / \mathrm{kg} / \mathrm{min}$ of remifentanil intravenously. The trachea was intubated with a left-sided 37-French (Fr) double-lumen tube, followed by an insertion of a TEE probe CX-50 TEE machine (Philips Medical Systems Andover, MA). A central venous catheter and pulmonary artery catheter were placed in the left internal jugular vein, and a $16-\mathrm{Fr}$ venous cannula was inserted through the right internal jugular vein for drainage of the superior vena cava, with the tip at the junction of the superior vena cava and innominate vein. Anesthesia was maintained with $1.5 \%$ of sevoflurane in oxygen, continuous infusions of $0.2-0.4 \mu \mathrm{g} / \mathrm{kg} / \mathrm{min}$ of remifentanil, and $4 \mathrm{mg} / \mathrm{kg} / \mathrm{h}$ of propofol.

TEE showed posterior leaflet prolapse (P2) with a marked eccentric jet in the mid-esophageal long-axis view (Fig. 1). After turning the probe clockwise from the mid-esophageal long-axis view, TEE showed a moderate

\section{Springer Open}

() The Author(s). 2020 Open Access This article is licensed under a Creative Commons Attribution 4.0 International License, which permits use, sharing, adaptation, distribution and reproduction in any medium or format, as long as you give appropriate credit to the original author(s) and the source, provide a link to the Creative Commons licence, and indicate if changes were made. The images or other third party material in this article are included in the article's Creative Commons licence, unless indicated otherwise in a credit line to the material. If material is not included in the article's Creative Commons licence and your intended use is not permitted by statutory regulation or exceeds the permitted use, you will need to obtain permission directly from the copyright holder. To view a copy of this licence, visit http://creativecommons.org/licenses/by/4.0/. 


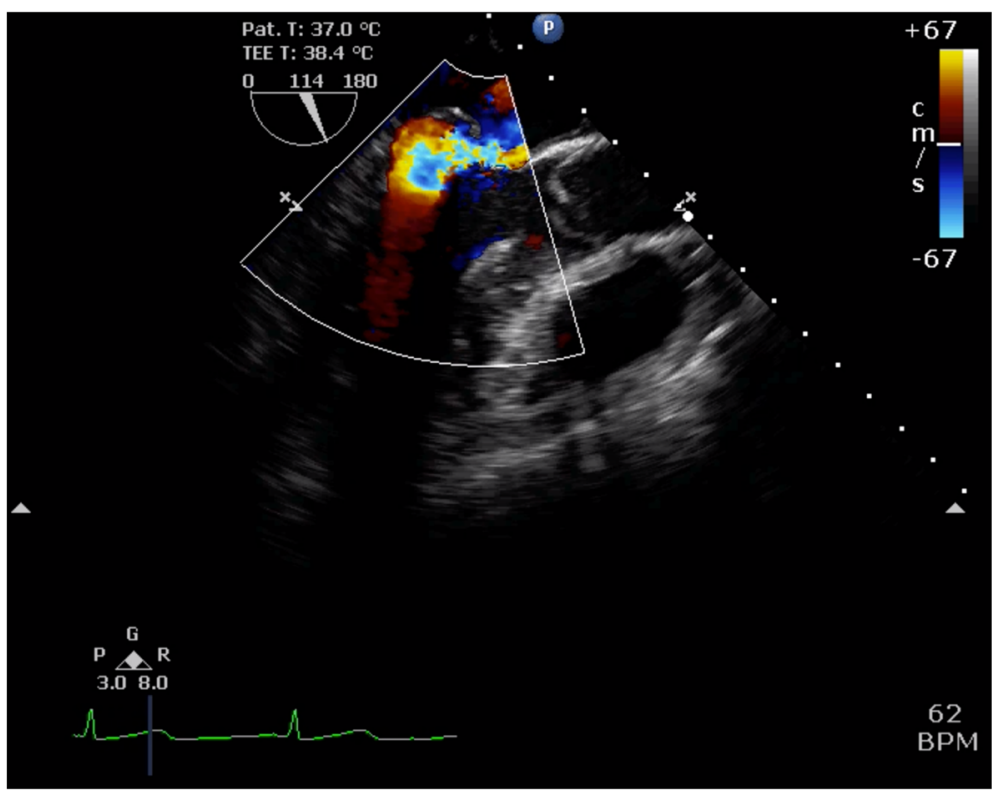

Fig. 1 Mid-esophageal long-axis view showing eccentric mitral valve regurgitation due to P2 prolapse

central regurgitation jet (Fig. 2). In the mid-esophageal commissure view, the "cobra head sign" indicating P2 prolapse (Fig. 3a) was noted. Moreover, a central regurgitation jet that was induced between the anterior leaflet (A3) and posterior leaflet (P3) was observed (Fig. 3b).

The three-dimensional (3-D) en face view showed a profound indentation, indicating that the cleft between P2 and P3 was noted at early diastole (Fig. 4). TEE showed not only P2 prolapse but also a cleft between P2 and P3, and mitral regurgitation was caused by both etiologies.

After establishing cardiopulmonary bypass (CPB), an antegrade cardioplegia cannula was inserted into the ascending aorta and a flexible cross-clamp was subsequently applied.

For the mitral valve repair procedure, posterior leaflet resection was not performed; instead, neochordal reconstruction of $\mathrm{P} 2$ and $\mathrm{P} 3$ and ring

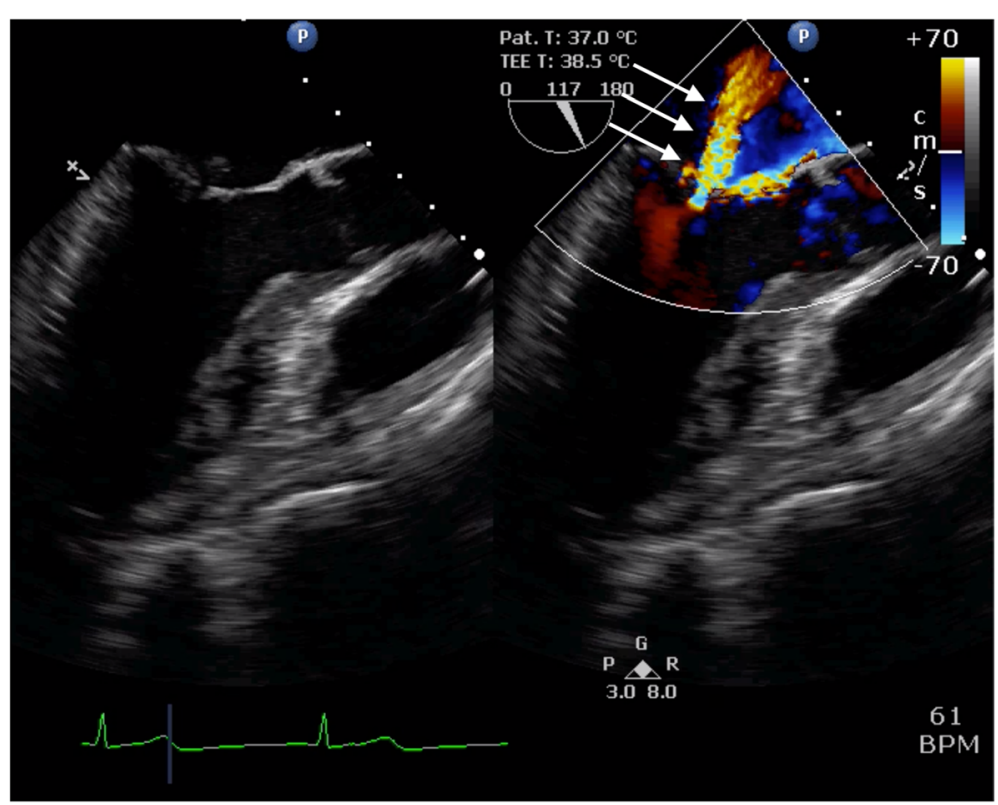

Fig. 2 Clockwise rotation of probe in the mid-esophageal long-axis view shows normal configuration of the mitral leaflets (A3-P3), however, a color Doppler image reveals a central mitral valve regurgitation jet with unknown etiology (white arrow) 

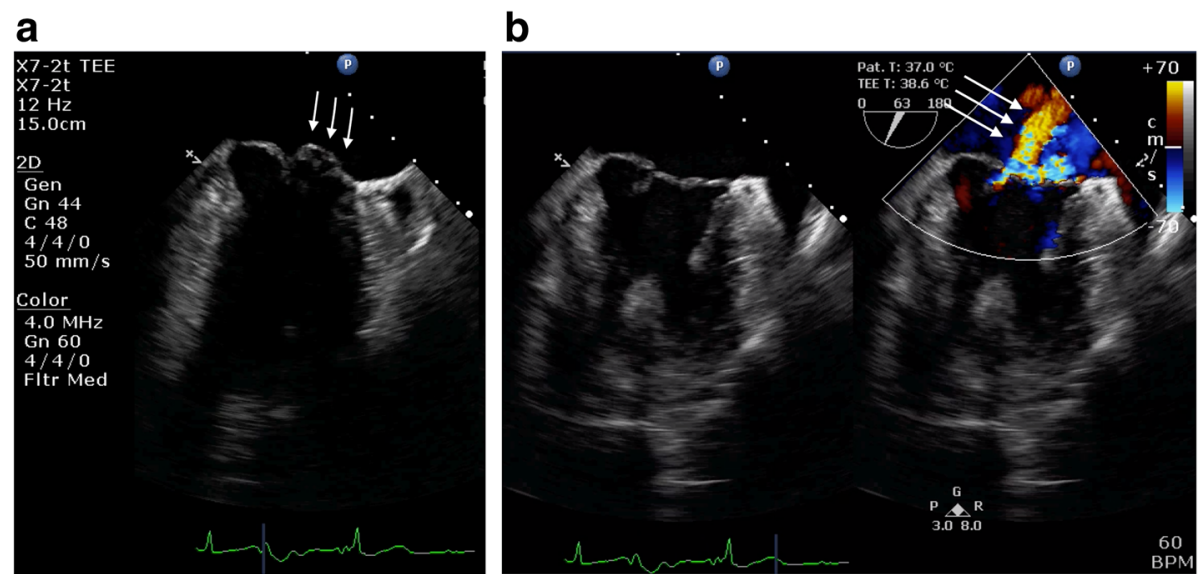

Fig. 3 a Mid-esophageal commissure view showing a "cobra head sign" indicating P2 prolapse (white arrow). b Mid-esophageal commissure view showing a central mitral valve regurgitation jet with unknown etiology between A3 and P3 (white arrow)

annuloplasty were performed due to the risk of cleft dilation after resecting the posterior leaflet. After declamping of the aorta, a $3 \mu \mathrm{g} / \mathrm{kg} / \mathrm{min}$ dopamine infusion was started. Weaning from $\mathrm{CPB}$ was very smooth. However, systolic anterior motion (SAM) occurred immediately after weaning from cardiopulmonary bypass. Dopamine was stopped to administrate. After volume loading and beta-blocker administration, SAM was improved. The hemodynamic status was stable. Subsequently, residual mitral regurgitation was not observed, and the postoperative course was uneventful.

\section{Discussion}

We found out two important clinical issues: firstly, intraoperative TEE, which is a combination of 2-D and 3-D echocardiography, was useful for diagnosing mitral regurgitation due to a cleft between P2 and P3 with P2 prolapse. Secondly, it was more useful for the selection of the mitral valve repair procedure by diagnosing the complicated mitral valve lesion which recognized the mitral regurgitation from the cleft.

After turning the probe clockwise from the midesophageal long-axis view, which indicates the modified mid-esophageal long-axis view, the view revealed the

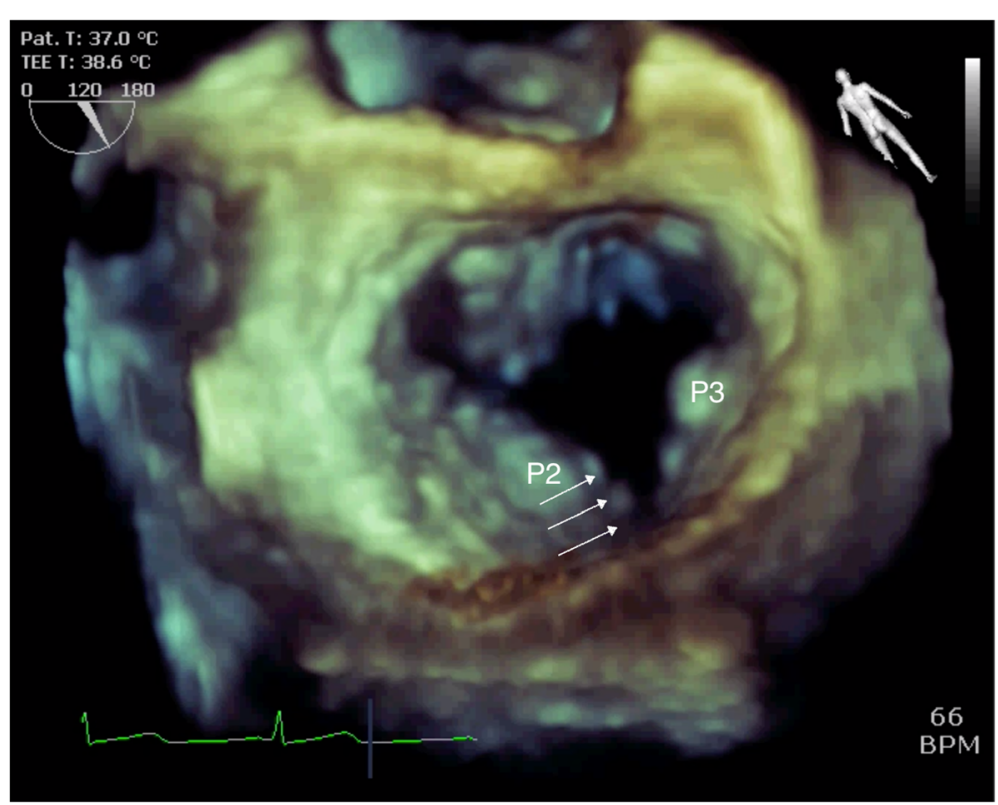

Fig. 4 Three-dimensional echocardiography at the en face view at early diastole showing a profound indentation (cleft) between P2 and P3 (white arrow) 
medial (A3-P3) side of the mitral valve. In the midesophageal commissure view, P3 and opposite site, which indicates not A2 but A3, was revealed. After turning the probe clockwise, a central mitral regurgitation jet was observed, although no prolapse was noted in the valve leaflets. In the mid-esophageal commissure view, a prolapse of A3 and P3 was not observed, but a central mitral regurgitation jet was observed. Finally, the 3-D en face view showed profound indentation in the mitral annulus indicating a cleft between P2 and P3. These results suggest that the central mitral regurgitation jet originated from the cleft of the posterior leaflet between P2 and P3.

In this case, mitral regurgitation was caused by the cleft between P2-3 in addition to the P2 prolapse. It also affected the selection of the operative method. For P2 prolapse, surgical resection of P2 is usually the choice for mitral valve repair. However, one cause of residual mitral regurgitation after mitral valve repair may be enlarged clefts. Therefore, in the case of mitral leaflet prolapse in conjunction with a cleft, there was a possibility that the risk of an enlarged cleft would increase with leaflet resection. Moreover, a cleft is a potential source of residual mitral regurgitation.

According to many reports, the frequency of mitral valve cleft is low. In a study using 2-D TEE, only $0.07 \%$ of patients with moderate or greater mitral regurgitation had a cleft on the posterior leaflet [2]. However, technological advances led to the emergence of 3-D echocardiography, and guidelines recommend that the mechanism of mitral regurgitation may be determined through the routine use of 3-D echocardiography [3]. In a study, 3-D echocardiography revealed the existence of a cleft in $3.3 \%$ of patients with moderate or greater mitral regurgitation [4]; $2.5 \%$ of these clefts were in the anterior leaflet and $0.8 \%$ in the posterior leaflet [4]. Thus, even with 3-D echocardiography, clefts in the posterior leaflet are rarely noted. This case is one of complex mitral valve lesions which indicates P2 prolapse and a cleft between P2 and P3.

In conclusion, we found that a complicated mitral valve lesion including P2 prolapse and a cleft between P2 and P3 was detected by 2-D and 3-D echocardiography using TEE. The presence or absence of mitral regurgitation from the cleft may also affect the choice of the mitral valve repair procedure.

\section{Supplementary information}

Supplementary information accompanies this paper at https://doi.org/10. 1186/s40981-020-00337-4.

Additional file 1: Video S1.

Abbreviations

TEE: Transesophageal echocardiography
Acknowledgements

None

Authors' contributions

KM collected the data from the case and drafted the manuscript. SS anesthetized the patient in the operating room and collected the data from the case. The authors read and approved the final manuscript.

Funding

Not applicable

Availability of data and materials

Not applicable

Ethics approval and consent to participate

Not applicable

Consent for publication

We obtained the consent to publish from the patient.

Competing interests

The authors declare that they have no competing interests.

Received: 15 January 2020 Accepted: 22 April 2020

Published online: 01 May 2020

References

1. Pisano C, Calia C, Ricasoli A, Fabio Triolo O, Argano V. Intraoperative transesophageal echocardiography for surgical repair of degenerative mitral regurgitation. J Heart Valve Dis. 2017;26(5):547-56.

2. Wyss CA, Enseleit F, van der Loo B, Grunenfelder J, Oechslin EN, Jenni R. Isolated cleft in the posterior mitral valve leaflet: a congenital form of mitral regurgitation. Clin Cardiol. 2009:32(10):553-60.

3. Zoghbi WA, Adams D, Bonow RO, Enriquez-Sarano M, Foster E, Grayburn PA, et al. Recommendations for noninvasive evaluation of native valvular regurgitation: a report from the American society of echocardiography developed in collaboration with the society for cardiovascular magnetic resonance. J Am Soc Echocardiogr. 2017;30(4):303-71.

4. Narang A, Addetia K, Weinert L, Yamat M, Shah AP, Blair JE, et al. Diagnosis of isolated cleft mitral valve using three-dimensional echocardiography. J Am Soc Echocardiogr. 2018;31(11):1161-7.

\section{Publisher's Note}

Springer Nature remains neutral with regard to jurisdictional claims in published maps and institutional affiliations.

\section{Submit your manuscript to a SpringerOpen ${ }^{\circ}$ journal and benefit from:}

- Convenient online submission

- Rigorous peer review

- Open access: articles freely available online

High visibility within the field

- Retaining the copyright to your article

Submit your next manuscript at $>$ springeropen.com 